\title{
Penetrating Brain Injury Caused by Retained Plastic Tip of Ballpoint Pen
}

\author{
Masaomi Koyanagi Nobuyuki Sakai Hidemitsu Adachi Yasushi Ueno \\ Takeharu Kunieda Hirotoshi Imamura Haruhiko Kikuchi \\ Department of Neurosurgery, Kobe City Medical Center General Hospital, Kobe, Japan
}

Intracranial extension after a low-velocity transorbital injury due to a sharp object is relatively rare but has been well documented in the pediatric population [1-7]. Penetrating brain injury has potentially serious and, in some cases, fatal consequences. In addition, it is generally difficult to acquire a medical history from children. Accurate and rapid multidisciplinary clinical and radiological evaluation of such injuries is essential $[4,7]$.

Here, we present a case in which a 2 -year-old girl sustained a transorbital penetrating brain injury caused by the retained tip of a ballpoint pen, which was clearly detected using multidetector row computed tomography (MDCT).

A 2-year-old girl was brought to the emergency room of our hospital, with complaints of hemorrhage in her right eye. She had been playing by herself in her mother's presence, when her mother noticed the girl crying, holding a ballpoint pen, and bleeding from her right eye.

On admission to our hospital, the girl was still crying but was conscious, and her motor functions were normal. Ophthalmological examination revealed laceration of the conjunctiva over the inner canthus of the right eye. This injury was considered to have occurred because of the penetration of the ballpoint pen. Importantly, the plastic tip of the ballpoint pen was not found.

\section{KARGER}

Fax +4161306 1234 E-Mail karger@karger.ch www.karger.com
(C) 2012 S. Karger AG, Basel

1016-2291/11/0476-0462\$38.00/0

Accessible online at:

www.karger.com/pne
Radiological evaluation was performed using a 64MDCT scanner without any sedation. Multiplanar reformation images clearly revealed a residual foreign body possibly the tip of the ballpoint pen - in the frontal lobe (fig. 1). Therefore, surgical removal of the foreign body was planned.

Bifrontal craniotomy was performed. The orbital roof was found to be fractured, and bone fragments were lodged in the dura mater. The tip of the pen was found in the frontal lobe and carefully removed using a microsurgical technique (fig. 2).

After the operation, the patient remained conscious, and no new neurological or ophthalmological deficits were observed. The postoperative MDCT scan showed no residual foreign body or intracranial hemorrhage. The patient was discharged on postoperative day 10 without any neurological deficit. During the follow-up period of 1 year, no apparent neurological event has occurred.

The institutional review board approved the publication of this case illustration.
Masaomi Koyanagi, MD, PhD

Department of Neurosurgery, Kobe City Medical Center General Hospital

Minatojima-Nakamachi 4-6, Chuo-ku

Kobe 650-0046 (Japan)

Tel. +81 78302 4321, E-Mail koyamagm@gmail.com 


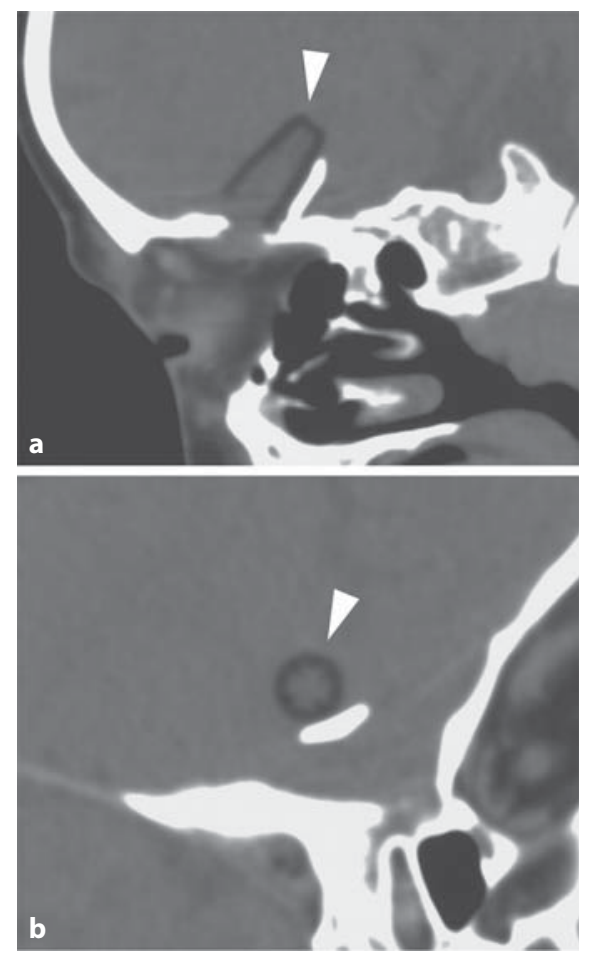

Fig. 1. a, b Nonenhanced multiplanar reformation images of 64MDCT showing the retained end tip of the ballpoint pen in the frontal lobe (white arrowheads).

\section{Acknowledgements}

The authors thank Ms. Chie Takeuchi for her technical assistance in radiological surveys.
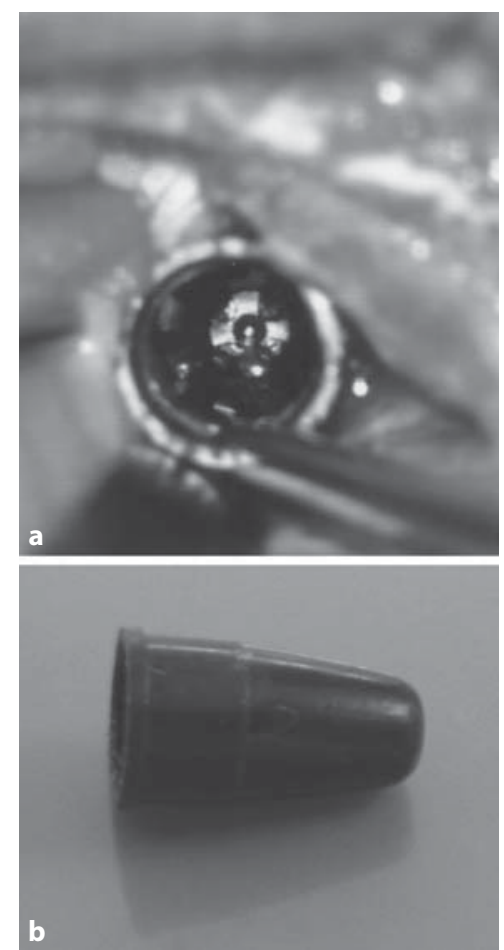

Fig. 2. a Intraoperative photograph showing the plastic tip of the ballpoint pen in the frontal lobe. $\mathbf{b}$ Photograph demonstrating the removed plastic tip of the ballpoint pen.

\section{Disclosure Statement}

The authors report no conflicts of interest concerning the materials or methods used in this study or the findings specified in this paper. None of the authors received any financial or material support for this study.

\section{References}

1 Agrawal A, Pratap A, Agrawal CS, Kumar A, Rupakheti S: Transorbital orbitocranial penetrating injury due to bicycle brake handle in a child. Pediatr Neurosurg 2007;43:498-500.

$\checkmark 2$ Davis GA, Holmes AD, Klug GL: Delayed presentation of transorbital intracranial pen. J Clin Neurosci 2000;7:545-548.

-3 Jacob JT, Cohen-Gadol AA, Maher CO, Meyer FB: Transorbital penetrating brainstem injury in a child: case report. J Neurosurg 2005;102:350-352.
4 Mono J, Hollenberg RD, Harvey JT: Occult transorbital intracranial penetrating injuries. Ann Emerg Med 1986;15:589-591.

5 Park SH, Cho KH, Shin YS, Kim SH, Ahn YH, Cho KG, Yoon SH: Penetrating craniofacial injuries in children with wooden and metal chopsticks. Pediatr Neurosurg 2006; 42:138-146.
Turbin RE, Maxwell DN, Langer PD, Frohman LP, Hubbi B, Wolansky L, Mori M: Patterns of transorbital intracranial injury: a review and comparison of occult and non-occult cases. Surv Ophthalmol 2006;51: 449-460.

7 Schreckinger M, Orringer D, Thompson BG, La Marca F, Sagher O: Transorbital penetrating injury: case series, review of the literature, and proposed management algorithm. J Neurosurg 2011;114:53-61. 